Invited Papers

\title{
Next generation of Fabry-Perot sensors for high-temperature
}

\author{
Marta S. Ferreira ${ }^{\mathrm{a}, \mathrm{b}, *}$, Paulo Roriz ${ }^{\mathrm{a}}$, Susana O. Silva ${ }^{\mathrm{a}, \mathrm{b}}$, José L. Santos ${ }^{\mathrm{a}, \mathrm{b}}$, Orlando Frazão ${ }^{\mathrm{a}}$ \\ ${ }^{a}$ INESC Porto, Rua do Campo Alegre 687, 4169-007 Porto, Portugal \\ ${ }^{\mathrm{b}}$ Dept. de Física e Astronomia da Faculdade de Ciências da Universidade do Porto, Rua do Campo Alegre 687, 4169-007 Porto, Portugal
}

\section{A R T I C L E I N F O}

Article history:

Available online 17 August 2013

Keywords:

Optical fiber sensors

Fabry-Perot interferometer

Temperature

\begin{abstract}
A B S T R A C T
This paper presents an overview of optical fiber sensors based on Fabry-Perot interferometers with a focus on high temperature applications. The next generation of these fiber types interferometers are based in photonic crystal fibers, microfabrication as well as by chemical etching of special structures. High temperature measurements with linear behavior are observed namely in un-doped fibers, i.e., with a pure silica composition. Three new configurations are presented as possible solutions to be considered in extreme conditions.
\end{abstract}

(c) 2013 Elsevier Inc. All rights reserved.

\section{Introduction}

The use of sensors in extreme temperature conditions is of vital importance for many industries, such as car, aerospace, military, oil, among others. The real time monitoring of this parameter is requested in spite of the harsh conditions. Optical fiber sensors are very suitable to be used in such conditions provided their robustness and ability to achieve high sensitivities.

Optical fiber sensors based on Fabry-Perot (FP) cavities have been widely explored over the last decades [1]. The first paper, published in 1981, described an extrinsic FP configuration [2]. In such case, the cavity is external to the fiber and the two mirrors required to form the cavity are formed by the fiber tips that are close enough to ensure the cavity. Seven years later, the first paper about an intrinsic FP cavity was published by Lee et al. [3]. This configuration comprises the formation of the cavity inside the optical fiber. One possible solution is to use two fiber Bragg gratings in series forming the two mirrors [4]. However, generally the FP cavities can be formed by splicing an hollow-core fiber section between singlemode fiber (SMF) and a diaphragm; by splicing photonic crystal fibers (PCF); by splicing a section of sapphire fiber to SMF; by applying chemical etching, or even by performing micromachining.

In this paper, a review of these techniques is presented with special focus on the suitability of using these configurations to perform high-temperature sensing.

\footnotetext{
* Corresponding author at: INESC Porto, Rua do Campo Alegre 687, 4169-007 Porto, Portugal. Fax: +3512 6082799 .

E-mail address: ofrazao@inescporto.pt (M.S. Ferreira).
}

\section{Diaphragm-based configurations}

The most well-known FP interferometer configuration is based on an air cavity formed between the optical fiber tip and a diaphragm [5]. Usually, the device fabrication consists in three steps: firstly, the splice between the SMF and the hollow core fiber is made. Afterwards, the hollow core fiber is cleaved near the splice and according to the desired cavity size. Finally, another splice with a tiny section of SMF is cleaved forming a diaphragm. Different applications were demonstrated over the last three decades. A very interesting example is to apply pressure or acoustic sensing in the diaphragm, inducing the simultaneous change of the cavity length and phase [6]. Recently a vapor-sensitive polymer layer was used as diaphragm, according to the scheme in Fig. 1, and new solution for gas sensing was demonstrated [7]. Another configuration well known by the scientific community is to apply a thin film on the tip of the fiber. One of the most common examples is to use it as a hydrogen sensor [8]. A different intrinsic FP interferometer can be obtained simply by fusion splicing two fibers with different core dimensions [9]. Multi-cavity FP interferometer has also been explored as a biosensor [10]. Recently two new FPs based on a diaphragm-free topology have been studied. The first was based on a pure silica diaphragm-free hollow tube configuration [11] and the second consisted on a hollow-core ring PCF [12]. Both configurations can be used to pressure sensing.

\section{PCF-based FP configurations}

Photonic crystal fiber (PCF)-based FP configurations have been studied over the past few years. Physical parameters as strain, temperature or refractive index have been considered, and due to the PCF intrinsic characteristics, sensors easy to manufacture and that presented reliable and repeatable good sensitivities were reported. 


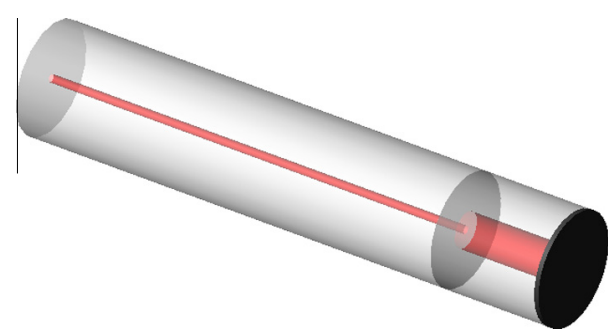

Fig. 1. FP cavity based on hollow-core fiber with diaphragm.

For instance, strain measurements were done by using a configuration based on a cavity formed by a hollow-core PCF spliced between two SMF [13]. The cavity could be several centimeters long and, besides being temperature independent, it exhibited an accuracy better than $5 \mu \varepsilon$. On the other hand, the fabrication of air bubbles both by splicing SMF with an index guiding PCF $[14,15]$ or a multimode PCF to SMF [16] were proposed to measure strain. Both configurations exhibited low thermal sensitivity, but good mechanical strength. Strain and temperature measurements were proposed in 2009 [17] with a configuration obtained by splicing a small section of suspended core fiber between SMF and a section of hollow core fiber (HCF). The presence of the HCF permitted the strain measurements. Two different suspended core fibers were tested and compared, one with three holes (Fig. 2) and other with four holes.

Refractive index (RI) measurements were done with a configuration composed by an endlessly SM PCF spliced between two sections of SMF [18]. The PCF was $\sim 2.3 \mathrm{~mm}$ long while the SMF cap length was of $\sim 20 \mu \mathrm{m}$. For a RI variation of $0.16 \mathrm{RIU}$, the fringes visibility varied and a sensitivity of $\sim 4.59$ /RIU was achieved. Temperature measurements up to $100{ }^{\circ} \mathrm{C}$ were also performed.

A different configuration, based on a HCF spliced between a PCF and a SMF was proposed in 2008 [19]. The sensor response to high temperatures was analyzed in the spatial frequency domain and different responses were observed for the frequencies obtained through the fast Fourier transform (FFT). A simple configuration was reported by Duan et al. [20]. By splicing two SMF sections with a large lateral offset, a high temperature sensor was obtained, which was able to operate over several temperature cycles. Still in the high-temperature measurements, a sensor was obtained by splicing an endlessly SM-PCF to the cleaved end facet of a SMF with an intentional complete collapse at the splice joint [21]. Temperature measurements up to $1200^{\circ} \mathrm{C}$ led to an optical path difference sensitivity of $\sim 39.1 \mathrm{~nm} /{ }^{\circ} \mathrm{C}$. Finally, in 2012 a sensing head based on the splice of a short section of polarizationmaintaining PCF to SMF with a controllable offset was presented [22]. A sensitivity of $13.8 \mathrm{pm} /{ }^{\circ} \mathrm{C}$ was attained for a large temperature range from 33 to $600{ }^{\circ} \mathrm{C}$.

\section{Micromachining-based FP configurations}

The use of laser micromachining opened up a new path in optical fiber sensors based on FP cavities. The technique provides

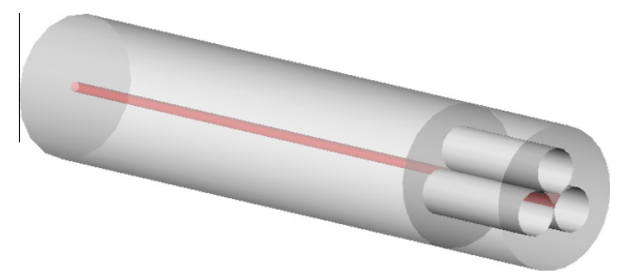

Fig. 2. FP cavity based on the three holes suspended core fiber. precise manufacture of micro-cavities that proved to be very sensitive to external medium variations or temperature. In 2008, the fabrication of an air cavity near the tip of a SMF and the fiber tip by using a 157-nm laser was reported [23]. The $29 \mathrm{~mm}$ long air cavity was temperature independent and when subjected to RI variations, a resolution of $\sim 4 \times 10^{-5}$ was attained. A micronotch formed by femtosecond laser was used to measure temperatures up to $1100^{\circ} \mathrm{C}$ [24] and RI of liquids [25]. In the former case, the cavity length sensitivity was of $0.074 \mathrm{pm} /{ }^{\circ} \mathrm{C}$. Regarding RI measurements, in the temperature range of $90{ }^{\circ} \mathrm{C}$ where they were performed, the cross-sensitivity to temperature was less than $1.1 \times 10^{-6} \mathrm{RIU} /{ }^{\circ} \mathrm{C}$.

In 2010, a SMF taper tip with direct micromachining of a micronotch cavity using focused-ion beam was proposed [26]. For temperatures up to $550{ }^{\circ} \mathrm{C}$, an average sensitivity of $\sim 17 \mathrm{pm} /{ }^{\circ} \mathrm{C}$ was reported. Finally, Zhou et al. presented a microchannel fabricated with a femtosecond laser inscription assisted chemical etching [27]. The microchannel was inscribed between two fiber Bragg gratings and the sensing structure was used to measure RI variations.

\section{Chemical etching based FP configurations}

FP sensors produced by etching were reported over the last few years. The detailed experimental procedure of this technique was reported in 2008 [28]. SM 800 optical fibers were etched and two of them were spliced to create the FP cavity, which was characterized in load. A sensing structure based on the splice between a SMF and an etched graded-index multimode fiber (GIF) has been proposed [29]. With this configuration, simultaneous measurement of RI and temperature of aqueous solutions was proposed. A similar configuration was reported, comparing the behavior of two different GIFs towards strain and temperature variations [30]. In the same year, a different configuration was proposed [31]. In this case, two GIF sections were spliced to SMF28 and then etched. After $8 \mathrm{~min}$. of exposure to HF, the two concavities were spliced, forming the cavity presented in Fig. 3.

The combination of an etched section of MMF between a SMF and a $\mathrm{SiO} 2$ diaphragm resulted in a pressure sensor capable of performing measurements with high sensitivity in spite of the small dimensions of the diaphragm [32]. The design of new special fibers to be subjected to post-processing can lead to very interesting sensing structures. In 2011, a new fiber design with a central region of $\mathrm{TiO}_{2}$, and a strongly doped $\mathrm{P}_{2} \mathrm{O}_{5}$ doped ring with a pure silica barrier in between was etched and spliced to a GIF section afterwards [33]. The FP cavity was subjected to temperatures above $650{ }^{\circ} \mathrm{C}$ and strain higher than $3000 \mu \varepsilon$. A cross-sensitivity of $0.055 \mu \varepsilon /{ }^{\circ} \mathrm{C}$ was attained.

\section{High temperature measurement}

In the last years, several new configurations were developed for high temperature. Topologies based on PCF are very interesting in this area since the fiber material is pure silica. However, by using

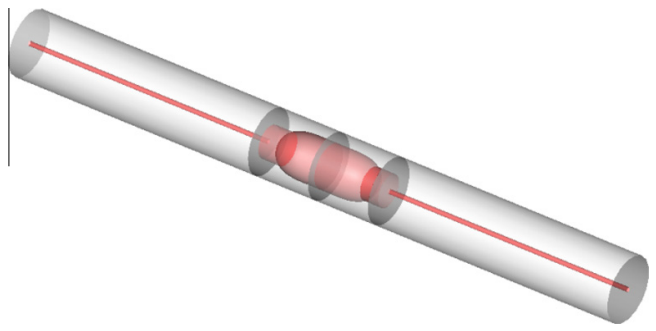

Fig. 3. FP cavity based on double concavities of etched GIF spliced to SMF28. 
Table 1

Characteristics of high temperature FP sensors.

\begin{tabular}{|c|c|c|c|}
\hline Configuration & Measurement Range & Sensitivity & Ref. \\
\hline Etching of special fiber with GIF & $20-650{ }^{\circ} \mathrm{C}$ & (Cavity length) $0.04 \mathrm{~nm} /{ }^{\circ} \mathrm{C}$ & [33] \\
\hline Etched GIF + SMF & $100-700{ }^{\circ} \mathrm{C}$ & $0.75 \mathrm{pm} /{ }^{\circ} \mathrm{C}$ & [31] \\
\hline Double-sided etched GIF + SMF & & $0.98 \mathrm{pm} /{ }^{\circ} \mathrm{C}$ & \\
\hline Etched GIF625 + SMF & $25-400{ }^{\circ} \mathrm{C}$ & $0.95 \mathrm{pm} /{ }^{\circ} \mathrm{C}$ & {$[30]$} \\
\hline Etched GIF50 + SMF & & $-0.84 \mathrm{pm} /{ }^{\circ} \mathrm{C}$ & \\
\hline PCF FP etalon formed by $157 \mathrm{~nm}$ laser & $18-800{ }^{\circ} \mathrm{C}$ & & {$[34]$} \\
\hline Micronotch formed by femtosecond laser & $50-1100{ }^{\circ} \mathrm{C}$ & $0.074 \mathrm{pm} /{ }^{\circ} \mathrm{C}$ & {$[24]$} \\
\hline SMF taper tip with micronotch cavity formed by FIB & $19-520^{\circ} \mathrm{C}$ & $17 \mathrm{pm} /{ }^{\circ} \mathrm{C}$ & {$[26]$} \\
\hline $\mathrm{PCF}+\mathrm{HCF}+\mathrm{SMF}$ & $50-1000{ }^{\circ} \mathrm{C}$ & & [19] \\
\hline Microscopic air bubble in SMF + PCF & $22-500{ }^{\circ} \mathrm{C}$ & $\sim 0.95 \mathrm{pm} /{ }^{\circ} \mathrm{C}$ & {$[15]$} \\
\hline 2 SMF spliced with large lateral offset & $200-1000{ }^{\circ} \mathrm{C}$ & $(\mathrm{OPD}) \sim 41 \mathrm{~nm} /{ }^{\circ} \mathrm{C}$ & {$[20]$} \\
\hline Air bubble in $\mathrm{PCF}+\mathrm{SMF}$ & $50-700{ }^{\circ} \mathrm{C}$ & $0.981 \mathrm{pm} /{ }^{\circ} \mathrm{C}$ & {$[16]$} \\
\hline Air bubble in SMF & $100-1000^{\circ} \mathrm{C}$ & $0.848 \mathrm{pm} /{ }^{\circ} \mathrm{C}$ & [35] \\
\hline Endlessly-SM PCF + SMF with collapse at splice joint & $25-1100{ }^{\circ} \mathrm{C}$ & $(\mathrm{OPD}) \sim 39.1 \mathrm{~nm} /{ }^{\circ} \mathrm{C}$ & {$[21]$} \\
\hline PM-PCF + SMF with offset & $33-600{ }^{\circ} \mathrm{C}$ & $13.8 \mathrm{pm} /{ }^{\circ} \mathrm{C}$ & {$[22]$} \\
\hline $\mathrm{SMF}+\mathrm{HCF}+$ diaphragm & $100-600{ }^{\circ} \mathrm{C}$ & & [5] \\
\hline $\mathrm{HCR} P C F+\mathrm{SMF}$ & $23-500{ }^{\circ} \mathrm{C}$ & $7.5 \mathrm{pm} /{ }^{\circ} \mathrm{C}$ (high temp) & [12] \\
\hline SMF + hollow-core silica tube & $23-1000{ }^{\circ} \mathrm{C}$ & $8.11 \mathrm{pm} /{ }^{\circ} \mathrm{C}$ (high temp) & [11] \\
\hline 2 SMF with a $50 \mu \mathrm{m}$-diameter fiber in between & $0-300{ }^{\circ} \mathrm{C}$ & $25.9 \mathrm{pm} /{ }^{\circ} \mathrm{C}$ & {$[36]$} \\
\hline SMF + sapphire fiber & $256-1510^{\circ} \mathrm{C}$ & & [37] \\
\hline SMF + sapphire fiber with offset & $310-976{ }^{\circ} \mathrm{C}$ & & [38] \\
\hline
\end{tabular}

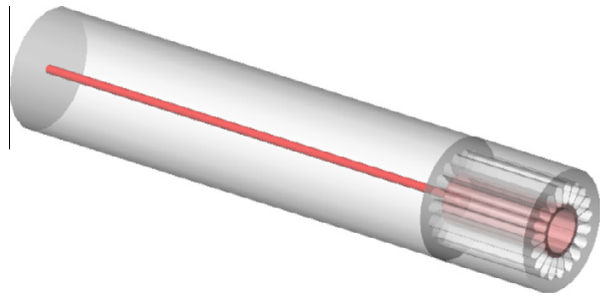

Fig. 4. FP based on hollow-core ring PCF.

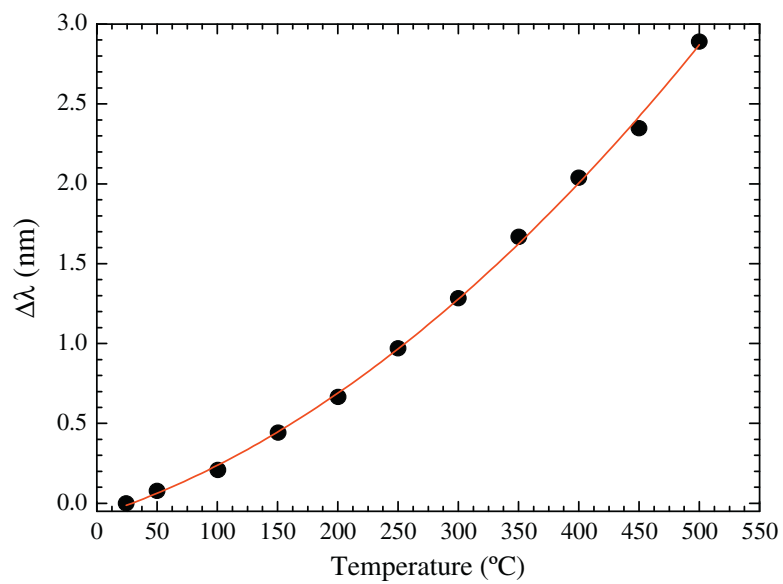

Fig. 5. Temperature response of the $508 \mu \mathrm{m}$ long sensing head.

sapphire fibers, sensors that achieve temperatures higher than $1500{ }^{\circ} \mathrm{C}$ can be obtained. Furthermore, geometries based on chemical etching or femtosecond technique are alternative solutions. All the configurations present interesting behaviors when subjected to high temperature, as can be seen on Table 1. In this section, new FP configurations based on PCF are presented, with diaphragm-free or using a piece of core less fiber $(50 \mu \mathrm{m})$ spliced with a large offset. All temperature measurements were done by placing the sensing head in a tubular oven, with an error associated to temperature reading smaller than $0.1^{\circ} \mathrm{C}$.

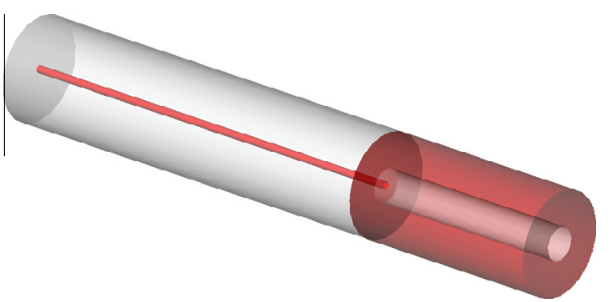

Fig. 6. FP cavity based on diaphragm-free silica tube.

The first configuration for high temperature is based on a hollow-core ring PCF. This FP cavity was created by splicing a small section of the large hollow-core ring PCF (HCR-PCF) to standard single mode fiber (SMF28). The splice was mainly applied in the SMF28 region to avoid collapsing the holes in the HCR-PCF. Fig. 4 presents the schematic design of the HCR-PCF based FP. This fiber has a large hollow core, with a diameter of $44.4 \mu \mathrm{m}$ and several petal shaped holes with an azimuthal diameter of $24.4 \mu \mathrm{m}$. In between these two structures, there is a $3.1 \mu \mathrm{m}$ thick silica ring. The cavity is formed when light travelling from the SMF end face excites the PCF ring. Afterwards, it is reflected due to the HCRPCF end face cleavage, being recoupled to the SMF. The spectral response depends on the FP cavity length.

By subjecting the sensing head to a temperature variation of $\sim 475^{\circ} \mathrm{C}$, a variation in wavelength was observed, according to Fig. 5. This behavior can be well adjusted to the second order polynomial. Nevertheless, two different linear regions can be considered, for lower and higher temperatures. The sensitivity obtained for temperatures below $200{ }^{\circ} \mathrm{C}$ was $\sim 3.8 \mathrm{pm} /{ }^{\circ} \mathrm{C}$, whereas for temperatures above that value the sensitivity achieved was of $\sim 7.5 \mathrm{pm} /{ }^{\circ} \mathrm{C}$. Since these values are positive, it can be stated that the thermal expansion is the dominant effect.

The second configuration was obtained by splicing SMF28 to a section of hollow-core rod, which had a core diameter of $20 \mu \mathrm{m}$. As described in the previous situation, the arc discharge was mainly applied to the SMF28 region. The hollow-core rod was then cleaved according to the desired cavity length. The spacing between the splice and the end face of the open hollow-core silica rod forms the Fabry-Pérot (FP) cavity. Light that travels inside the SMF28 is reflected at its end face, but a fraction is also transmitted into the walls of the hollow rod. When this light reaches 


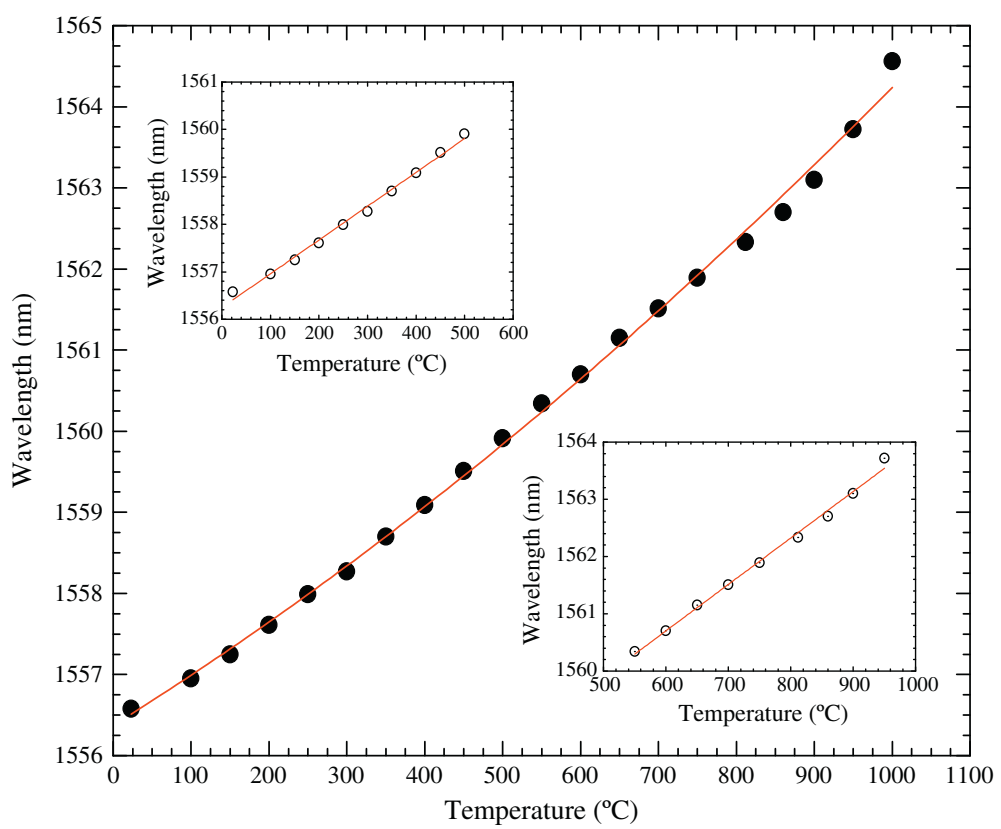

Fig. 7. Temperature response of the sensing head. Inset 1 (top left): low temperatures response; inset 2 (bottom right): high temperatures response.

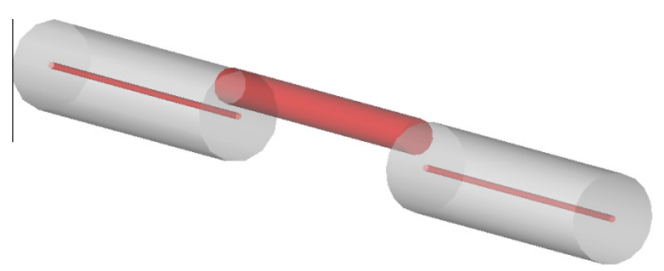

Fig. 8. Band rejection filter configuration.

the rod end, Fresnel reflection occurs and a fraction of this light is recoupled again into the SMF28 (Fig. 6).

Fig. 7 presents the optical response of a $140 \mu \mathrm{m}$-long sensing head for a temperature variation ranging from $23^{\circ} \mathrm{C}$ (room temperature) to $1000^{\circ} \mathrm{C}$. The experimental results are well adjusted by the second order polynomial.

$$
\Delta \lambda=1.868 \times 10^{-5} T^{2}+0.006 T+1556.373
$$

However, it is reasonable to divide the temperature range in two different regions, for low and high temperatures (insets Fig. 7), where a linear approximation can be done. The sensitivities obtained were of $7.12 \mathrm{pm} /{ }^{\circ} \mathrm{C}$ and $8.11 \mathrm{pm} /{ }^{\circ} \mathrm{C}$, respectively.

The last configuration is based on an offset splice between different diameters of optical fiber with high or low finesse [36,39]. To demonstrate the proposed configuration, the sensing head structure shown in Fig. 8 was implemented. It consisted of a $2 \mathrm{~mm}$-long silica rod with $50 \mu \mathrm{m}$ diameter spliced between two standard SMF28 (8.2 and $125 \mu \mathrm{m}$ of core and cladding diameters, respectively) where a strong misalignment was imposed so that the $50 \mu \mathrm{m}$-fiber could not touch the core of both SMFs. The fiber device behaves similarly to an FP interferometer, either in transmission or in reflection, according to the misalignment position between the $50 \mu \mathrm{m}$-fiber and the lead-out SMF (see the sensing head detail in Fig. 8).

In the fabrication process it was used a fusion splicing machine in manual operation with an electric arc of $70 \mathrm{~mA}$ and the duration time was of $400 \mathrm{~ms}$. The discharge was applied in the SMF28 region with an offset of $20 \mu \mathrm{m}$. The splicing process is very important because it should avoid the destruction of the SMF28 core. The first

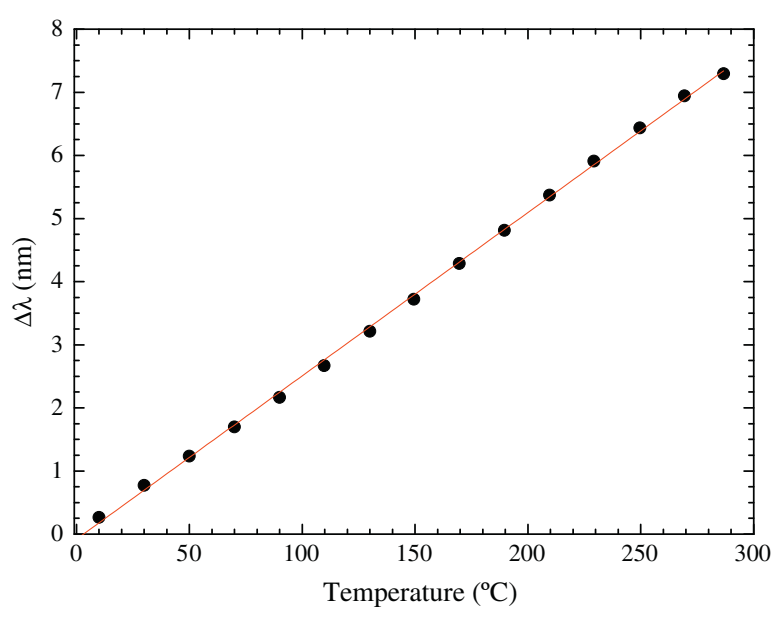

Fig. 9. Wavelength shift versus temperature variation for the band rejection configuration.

splice (between the lead-in SMF28 and the $50 \mu \mathrm{m}$-fiber) was monitored in real time with an optical spectrum analyzer (OSA) and the Fresnel reflection at the fiber end was observed. The second splice (between the $50 \mu \mathrm{m}$-fiber and the lead-out SMF28) was monitored in transmission during the misalignment of the fibers in order to obtain the desired optical spectrum of the intended new device. When the lead-out fiber was aligned with the lead-in, a bandrejection filter was obtained. The results depicted in Fig. 9 indicate that structure exhibit linear response to temperature variations with a sensitivity of $25.6 \mathrm{pm} /{ }^{\circ} \mathrm{C}$, respectively. This was somewhat expected since the temperature variation does not change the SMF-silica rod launching conditions; the results are determined by the temperature dependence of the refractive index and the thermal expansion of the silica fiber material.

\section{Conclusions}

Summarizing, this paper reviews the most promising FP cavities developed for high temperature measurement. The described 
configurations may be divided into three main categories: the first one generally uses the splice machine and includes the most conventional FP cavities based on diaphragms at the fiber tip. The appearance of diaphragm-free FP cavities has become an alternative to conventional ones, where the light travels inside a pure silica hollow tube and it is reflected at the fiber end due to the cut made by the cut machine. Another topology relies on multimode or other specialty fibers submitted to chemical etching. These FP configurations are potentially more attractive to be used in specific applications such as in gas detection. Finally, FP cavities developed by means of microfabrication, either using electric arc discharge or femtosecond laser technique, have also become promising configurations for sensing. With the emergence of microstructured fibers, novel configurations were developed for a wide range of applications, which presented almost linear sensitivities to high temperatures. The next step in this area is the development of FP devices using optical fibers with asymmetric index profiles that may be subjected to post-processing.

\section{References}

[1] Y.J. Rao, Recent progress in fiber-optic extrinsic Fabry-Perot interferometric sensors, Optical Fiber Technology 12 (2006) 227-237.

[2] S.J. Petuchowski, T.G. Giallorenzi, S.K. Sheem, A sensitive fiberoptic FabryPerot-interferometer, IEEE Journal of Quantum Electronics 17 (1981) 21682170.

[3] C.E. Lee, H.F. Taylor, Interferometric Optical Fiber Sensors Using Internal Mirrors, Electronics Letters 24 (1988) 193-194.

[4] X.K. Wan, H.F. Taylor, Intrinsic fiber Fabry-Perot temperature sensor with fiber Bragg grating mirrors, Optics Letters 27 (2002) 1388-1390.

[5] X.W. Wang, J.C. Xu, Y.Z. Zhu, K.L. Cooper, A.B. Wang, All-fused-silica miniature optical fiber tip pressure sensor, Optics Letters 31 (2006) 885-887.

[6] J.C. Xu, X.W. Wang, K.L. Cooper, A.B. Wang, Miniature all-silica fiber optic pressure and acoustic sensors, Optics Letters 30 (2005) 3269-3271.

[7] J. Liu, Y.Z. Sun, X.D. Fan, Highly versatile fiber-based optical Fabry-Perot gas sensor, Optics Express 17 (2009) 2731-2738.

[8] M.A. Butler, Micromirror optical-fiber hydrogen sensor, Sensors and Actuators B - Chemical 22 (1994) 155-163.

[9] W.H. Tsai, C.J. Lin, A novel structure for the intrinsic Fabry-Perot fiber-optic temperature sensor, Journal of Lightwave Technology 19 (2001) 682-686.

[10] Y. Zhang, H. Shibru, K.L. Cooper, A.B. Wang, Miniature fiber-optic multicavity Fabry-Perot interferometric biosensor, Optics Letters 30 (2005) 1021-1023.

[11] M.S. Ferreira, L. Coelho, K. Schuster, J. Kobelke, J.L. Santos, O. Frazao, FabryPerot cavity based on a diaphragm-free hollow-core silica tube, Optics Letters 36 (2011) 4029-4031.

[12] M.S. Ferreira, J. Bierlich, H. Lehmann, K. Schuster, J. Kobelke, J.L. Santos, O Frazao, Fabry-Perot cavity based on hollow-core ring photonic crystal fiber for pressure sensing, IEEE Photonics Technology Letters 24 (2012) 2122-2124.

[13] Y.J. Rao, T. Zhu, X.C. Yang, D.W. Duan, In-line fiber-optic etalon formed by hollow-core photonic crystal fiber, Optics Letters 32 (2007) 2662-2664.

[14] F.C. Favero, L. Araujo, G. Bouwmans, V. Finazzi, J. Villatoro, V. Pruneri, Spheroidal Fabry-Perot microcavities in optical fibers for high-sensitivity sensing, Optics Express 20 (2012) 7112-7118.

[15] J. Villatoro, V. Finazzi, G. Coviello, V. Pruneri, Photonic-crystal-fiber-enabled micro-Fabry-Perot interferometer, Optics Letters 34 (2009) 2441-2443.

[16] M. Deng, C.P. Tang, T. Zhu, Y.J. Rao, PCF-based Fabry-Perot interferometric sensor for strain measurement at high temperatures, IEEE Photonics Technology Letters 23 (2011) 700-702.

[17] O. Frazao, S.H. Aref, J.M. Baptista, J.L. Santos, H. Latifi, F. Farahi, J. Kobelke, K. Schuster, Fabry-Perot cavity based on a suspended-core fiber for strain and temperature measurement, IEEE Photonics Technology Letters 21 (2009) $1229-1231$.

[18] Y.J. Rao, M. Deng, D.W. Duan, T. Zhu, In-line fiber Fabry-Perot refractive-index tip sensor based on endlessly photonic crystal fiber, Sensors and Actuators A Physical 148 (2008) 33-38.

[19] H.Y. Choi, K.S. Park, S.J. Park, U.C. Paek, B.H. Lee, E.S. Choi, Miniature fiber-optic high temperature sensor based on a hybrid structured Fabry-Perot interferometer, Optics Letters 33 (2008) 2455-2457.

[20] D.W. Duan, Y.J. Rao, W.P. Wen, J. Yao, D. Wu, L.C. Xu, T. Zhu, In-line all-fibre Fabry-Perot interferometer high temperature sensor formed by large lateral offset splicing, Electronics Letters 47 (2011) 401-402.

[21] L.C. Xu, M. Deng, D.W. Duan, W.P. Wen, M. Han, High-temperature measurement by using a PCF-based Fabry-Perot interferometer, Optics and Lasers in Engineering 50 (2012) 1391-1396.

[22] J. Zhang, H. Sun, Q.Z. Rong, Y. Ma, L. Liang, Q.F. Xu, P. Zhao, Z.Y. Feng, M.L. Hu, X.G. Qiao, High-temperature sensor using a Fabry-Perot interferometer based on solid-core photonic crystal fiber, Chinese Optics Letters 10 (2012).

[23] Z.L. Ran, Y.J. Rao, W.J. Liu, X. Liao, K.S. Chiang, Laser-micromachined FabryPerot optical fiber tip sensor for high-resolution temperature-independent measurement of refractive index, Optics Express 16 (2008) 2252-2263.

[24] T. Wei, Y.K. Han, H.L. Tsai, H. Xiao, Miniaturized fiber inline Fabry-Perot interferometer fabricated with a femtosecond laser, Optics Letters 33 (2008) $536-538$.

[25] T. Wei, Y.K. Han, Y.J. Li, H.L. Tsai, H. Xiao, Temperature-insensitive miniaturized fiber inline Fabry-Perot interferometer for highly sensitive refractive index measurement, Optics Express 16 (2008) 5764-5769.

[26] J.L. Kou, J. Feng, L. Ye, F. Xu, Y.Q. Lu, Miniaturized fiber taper reflective interferometer for high temperature measurement, Optics Express 18 (2010) $14245-14250$

[27] K.M. Zhou, Z.J. Yan, L. Zhang, I. Bennion, Refractometer based on fiber Bragg grating Fabry-Perot cavity embedded with a narrow microchannel, Optics Express 19 (2011) 11769-11779.

[28] V.R. Machavaram, R.A. Badcock, G.F. Fernando, Fabrication of intrinsic fibre Fabry-Perot sensors in silica fibres using hydrofluoric acid etching, Sensors and Actuators a-Physical 138 (2007) 248-260.

[29] Y.A. Gong, Y. Guo, Y.J. Rao, T.A. Zhao, Y. Wu, Fiber-optic fabry-perot sensor based on periodic focusing effect of graded-index multimode fibers, IEEE Photonics Technology Letters 22 (2010) 1708-1710.

[30] P.A.R. Tafulo, P.A.S. Jorge, J.L. Santos, F.M. Araujo, O. Frazao, Intrinsic FabryPerot cavity sensor based on etched multimode graded index fiber for strain and temperature measurement, IEEE Sensors Journal 12 (2012) 8-12.

[31] P.A.R. Tafulo, P.A.S. Jorge, J.L. Santos, O. Frazao, Fabry-Perot cavities based on chemical etching for high temperature and strain measurement, Optics Communications 285 (2012) 1159-1162.

[32] D. Donlagic, E. Cibula, All-fiber high-sensitivity pressure sensor with $\mathrm{SiO}_{2}$ diaphragm, Optics Letters 30 (2005) 2071-2073.

[33] S. Pevec, D. Donlagic, All-fiber, long-active-length Fabry-Perot strain sensor, Optics Express 19 (2011) 15641-15651.

[34] Z.L. Ran, Y.J. Rao, H.Y. Deng, X. Liao, Miniature in-line photonic crystal fiber etalon fabricated by $157 \mathrm{~nm}$ laser micromachining, Optics Letters 32 (2007) 3071-3073.

[35] D.W. Duan, Y.J. Rao, Y.S. Hou, T. Zhu, Microbubble based fiber-optic FabryPerot interferometer formed by fusion splicing single-mode fibers for strain measurement, Applied Optics 51 (2012) 1033-1036.

[36] S. Silva, L. Coelho, R.M. Andre, O. Frazao, Gas refractometry based on an allfiber spatial optical filter, Optics Letters 37 (2012) 3450-3452.

[37] A. Wang, S. Gollapudi, K.A. Murphy, R.G. May, R.O. Claus, Sapphire-fiber-based intrinsic Fabry-Perot-interferometer, Optics Letters 17 (1992) 1021-1023.

[38] A. Wang, S. Gollapudi, R.G. May, K.A. Murphy, R.O. Claus, Advances in sapphirefiber-based intrinsic interferometric sensors, Optics Letters 17 (1992) 15441546.

[39] D.W. Duan, Y.J. Rao, T. Zhu, High sensitivity gas refractometer based on allfiber open-cavity Fabry-Perot interferometer formed by large lateral offset splicing, Journal of the Optical Society of America B - Optical Physics 29 (2012) 912-915. 